\title{
Hospital Medicine Resident Training Tracks: Developing the Hospital Medicine Pipeline
}

\author{
Joseph R. Sweigart, MD ${ }^{1,2 *}$, Darlene Tad-y, MD³, Patrick Kneeland, MD³, Mark V. Williams, MD', Jeffrey J. Glasheen, MD³
}

IInternal Medicine, Albert B. Chandler Hospital, University of Kentucky, Lexington, Kentucky; ${ }^{2}$ Lexington VA Medical Center, Lexington, Kentucky; ${ }^{3}$ University of Colorado School of Medicine, Aurora, Colorado.

BACKGROUND: Hospital medicine $(\mathrm{HM})$ is rapidly evolving into new clinical and nonclinical roles. Traditional internal medicine (IM) residency training likely does not optimally prepare residents for success in HM. Hospital medicine residency training tracks may offer a preferred method for specialized HM education.

METHODS: Internet searches and professional networks were used to identify HM training tracks. Information was gathered from program websites and discussions with track directors.

RESULTS: The $11 \mathrm{HM}$ tracks at academic medical centers across the United States focus mostly on senior residents. Track structure and curricular content are determined largely by the structure and curricula of the IM residency programs in which they exist. Almost all tracks feature experiential quality improvement projects. Content on healthcare eco- nomics and value is common, and numerous track leaders report this content is expanding from $\mathrm{HM}$ tracks into entire residency programs. Tracks also provide opportunities for scholarship and professional development, such as workshops on abstract creation and job procurement skills. Almost all tracks include HM preceptorships as well as rotations within various disciplines of HM.

CONCLUSIONS: HM residency training tracks focus largely on quality improvement, health care economics, and professional development. The structures and curricula of these tracks are tightly linked to opportunities within IM residency programs. As HM continues to evolve, these tracks likely will expand to bridge clinical and extra-clinical gaps between traditional IM training and contemporary HM practice. Journal of Hospital Medicine 2017;12:173-176. (C) 2017 Society of Hospital Medicine
The field of hospital medicine (HM) is rapidly expanding in the areas of clinical medicine, administration, and quality improvement (QI). ${ }^{1}$ Emerging with this growth is a gap in the traditional internal medicine (IM) training and skills needed to be effective in HM. ${ }^{1,2}$ These skills include clinical and nonclinical aptitudes, such as process improvement, health care economics, and leadership..$^{1-3}$ However, resident education on these topics must compete with other required curricular content in IM residency training. ${ }^{2,4}$ Few IM residencies offer focused HM training that emphasizes key components of successful HM careers. ${ }^{3,5}$

Within the past decade, designated HM tracks within IM residency programs have been proposed as a potential solution. Initially, calls for such tracks focused on gaps in the clinical competencies required of hospitalists. ${ }^{1}$ Tracks have since evolved to also include skills required to drive high-value care, process improvement, and scholarship. Designated HM tracks address these areas through greater breadth of curricula, additional time for reflection, participation in group projects, and active application to clinical care. ${ }^{4}$ We conducted a study to identify themes that could inform the ongoing evolution of dedicated HM tracks.

\footnotetext{
*Address for correspondence and reprint requests: Joseph R. Sweigart, MD, Internal Medicine, Albert B. Chandler Hospital, University of Kentucky, 800 Rose St, MN602, Lexington, KY 40536-0294; Telephone: 859-323-6047; Fax: 859257-3873; E-mail: joseph.sweigart@uky.edu
}

Received: June 6, 2016; Revised: August 29, 2016; Accepted: August 29, 2016

2017 Society of Hospital Medicine DOI 10.12788/jhm.2703

\section{METHODS}

Programs were initially identified through communication among professional networks. The phrases hospital medicine residency track and internal medicine residency hospitalist track were used in broader Google searches, as there is no database of such tracks. Searches were performed quarterly during the 2015-2016 academic year. The top 20 hits were manually filtered to identify tracks affiliated with major academic centers. IM residency program websites provided basic information for programs with tracks. We excluded tracks focused entirely on $\mathrm{QI}^{6}$ because, though a crucial part of HM, QI training alone is probably insufficient for preparing residents for success as hospitalists on residency completion. Similarly, IM residencies with stand-alone HM clinical rotations without longitudinal HM curricula were excluded.

Semistructured interviews with track directors were conducted by e-mail or telephone for all tracks except one, the details of which are published. ${ }^{7}$ We tabulated data and reviewed qualitative information to identify themes among the different tracks. As this study did not involve human participants, Institutional Review Board approval was not needed.

\section{RESULTS}

We identified $11 \mathrm{HM}$ residency training programs at major academic centers across the United States: Cleveland Clinic, Stanford University, Tulane University, University of California Davis, University of California Irvine, University of Colorado, University of Kentucky, University of Minnesota, University of New Mexico, Virginia Commonwealth University, and Wake 
TABLE 1. Demographic and Structural Characteristics of Current Hospital Medicine Tracks

\begin{tabular}{|c|c|c|c|}
\hline Track & $\begin{array}{l}\text { Start } \\
\text { Year }\end{array}$ & Participation Numbers and Duration & Primary Content Delivery Structure \\
\hline University of Colorado & 2001 & $\begin{array}{l}\text { 12/year for PGY-2 and PGY-3a } \\
2-6 \text { begin as interns in Hospitalist Leader's Track } \\
\text { Competitive selection }\end{array}$ & $\begin{array}{l}4 \text { hours every other month } \\
\text { Monthly journal club } \\
\text { Annual retreat }\end{array}$ \\
\hline Tulane University & 2003 & Variable participation all 3 years & Half a day every 5 weeks as part of Curriculum for Additional Skills \\
\hline Virginia Commonwealth University & 2005 & 5/year for PGY-2 and PGY-3a & $\begin{array}{l}1 \text { hour monthly } \\
\text { Occasional journal clubs on pertinent contemporary studies }\end{array}$ \\
\hline University of Minnesota & 2009 & $\begin{array}{l}\text { 4-6 for PGY-3 } \\
\text { Competitive selection }\end{array}$ & Alternating blocks of clinical and nonclinical obligations during designated rotations \\
\hline Cleveland Clinic & 2011 & $\begin{array}{l}\text { 3-6/year for PGY-2 and PGY-3 } \\
\text { Competitive selection }\end{array}$ & 2 consecutive months per year with alternating blocks of clinical and nonclinical obligations \\
\hline University of California Davis & 2014 & 2-6 for PGY-3 & 2-week block as kickoff for quality improvement project \\
\hline Stanford University & 2015 & 13 residents total for PGY-2 and PGY-3 & 10 seminars annually \\
\hline University of New Mexico & 2016 & 1-6/year for PGY-2 and PGY-3 & $\begin{array}{l}2 \text { hours monthly } \\
\text { Quarterly journal club }\end{array}$ \\
\hline \multicolumn{4}{|c|}{$\begin{array}{l}{ }^{2} \text { All residents are in a track (eg, hospital medicine, primary care, subspecialty). } \\
\text { 'TTrack has distinct match number. } \\
\text { NOTE: Abbreviation: PGY, postgraduate year. }\end{array}$} \\
\hline
\end{tabular}

Forest University (Table 1). We reviewed the websites of about 10 other programs, but none suggested existence of a track. Additional programs contacted reported no current track.

\section{Track Participants and Structure}

HM tracks mainly target third-year residents (Table 1 ). Some extend into the second year of residency, and 4 have opportunities for intern involvement, including a separate match number at Colorado. Tracks accept up to 12 residents per class. Two programs, at Colorado and Virginia, are part of IM programs in which all residents belong to a track (eg, HM, primary care, research).

HM track structures vary widely and are heavily influenced by the content delivery platforms of their IM residency programs. Several HM track directors emphasized the importance of fitting into existing educational frameworks to ensure access to residents and to minimize the burden of participation. Four programs deliver the bulk of their nonclinical content in dedicated blocks; 6 others use brief recurring sessions to deliver smaller aliquots longitudinally (Table 1). The number of protected hours for content delivery ranges from 10 to more than 40 annually. All tracks use multiple content delivery modes, including didactic sessions and journal clubs. Four tracks employ panel discussions to explore career options within HM. Several also use online platforms, including discussions, readings, and modules.

\section{Quality Improvement}

The vast majority of curricula prominently feature experiential QI project involvement (Table 2). These mentored longitudi- nal projects allow applied delivery of content, such as QI methods and management skills. Four tracks use material from the Institute for Healthcare Improvement. ${ }^{8}$ Several also offer dedicated QI rotations that immerse residents in ongoing QI efforts.

Institutional partnerships support these initiatives at several sites. The Minnesota track is a joint venture of the university and Regions Hospital, a nonprofit community hospital. The Virginia track positions HM residents to lead university-wide interdisciplinary QI teams. For project support, the Colorado and Kentucky tracks partner with local QI resources-the Institute for Healthcare Quality, Safety, and Efficiency at Colorado and the Office of Value and Innovation in Healthcare Delivery at Kentucky.

\section{Health Care Economics and Value}

Many programs leverage the rapidly growing emphasis on health care "value" as an opportunity for synergy between IM programs and HM tracks. Examples include involving residents in efforts to improve documentation or didactic instruction on topics such as health care finance. The New Mexico and Wake Forest tracks offer elective rotations on health care economics. Several track directors mentioned successfully expanding curricula on health care value from the HM track into IM residency programs at large, providing a measurable service to the residency programs while ensuring content delivery and freeing up additional time for track activities.

\section{Scholarship and Career Development}

Most programs provide targeted career development for residents. Six tracks provide sessions on job procurement 


\section{TABLE 2. Curricular Content Delivered in Current Hospital Medicine Tracks}

\begin{tabular}{llll}
\hline & & Healthcare & Scholarship and \\
Program & Quality and Safety & Economics and Value & Career Development \\
\hline University of California & QI methods & Covered elsewhere in IM residency & HM career panel \\
Davis & Project management & program content & Content on CV and cover letters \\
& Change management & & Formal Ql project mentors \\
& IH Open School modules & & No rotation \\
\hline
\end{tabular}

\begin{tabular}{ll}
\hline University of California Longitudinal project & Participate on hospital committees related Assigned mentors \\
Irvine & to longitudinal project
\end{tabular}
to longitudinal project

\section{Rotations}

Geriatric medicine

Palliative medicine

Preoperative medicine

Cleveland Clinic Quality and Safety Week

Group QI project

Covered elsewhere in IM residency

program content

Content on teaching and leadership

Leadership journal club

\section{Rotations}

Community hospitals

Palliative medicine
Informal mentorship

Perioperative week

Clinical journal club

\begin{tabular}{lll}
\hline University of & Ql methods & Didactic material on: \\
Colorado & Change management & Health care finance \\
& Stakeholder assessment & Business drivers \\
Longitudinal group Ql project & Resource utilization \\
IHI Open School modules & Physician billing \\
& High-value curriculum delivered during \\
& practicum
\end{tabular}

\begin{tabular}{llc}
\hline University of & Ql methods & Didactic material on: \\
Kentucky & Project management & Health care finance \\
& Change management & Billing and coding \\
& Longitudinal group QI project & Public reporting
\end{tabular}

\begin{tabular}{lll}
\hline University of & Ql project as pairs during PGY-2 and & Didactic material on: \\
Minnesota & PGY-3
\end{tabular}

HM career pane

Content on 5-year planning, CV and cover letters, interviewing, and contract negotiation

Sessions on abstract and poster creation and effective presentation strategies Assigned mentors

\section{$\begin{array}{ll}\text { Content on future planning, CV and cover } & \text { perioperative medicine } \\ \text { letters, and interviewing } & \text { Clinical journal club }\end{array}$}

Sessions on inpatient teaching strategies and abstract and poster creation

Resident-selected mentors
HM preceptorship each year

Rotations

Geriatric medicine

Palliative medicine

Perioperative medicine

Consultative medicine

Clinical journal club

HM preceptorship, including work with APPS, perioperative medicine, and consultations
Minnesota
Healthcare finance

Documentation and coding
SHM Leadership Academy as PGY-2 residents

$\mathrm{HM}$ retreat with $\mathrm{HM}$ group

Content on leadership

Assigned mentors

Medical Economics elective
Billing and coding
High-value care
Transitions of care

Transitions of care Content on CV, interviewing, and contract
negotiation
Sessions on abstract and poster creation and
physicians as teachers

Resident-selected QI mentors

\section{Rotations \\ Referring hospitals}

Transitional care unit

Perioperative medicine

Palliative medicine

Triage service

Pain service

Clinical journal club

Rotations

Consultative medicine

Ethics

Palliative medicine

Regional medical center

Clinical journal club

\begin{tabular}{lll}
\hline Stanford University & $\begin{array}{l}\text { Q elective rotation } \\
\text { Individual QI project }\end{array}$ & $\begin{array}{l}\text { Seminars on hospital efficiency and } \\
\text { healthcare reimbursement }\end{array}$
\end{tabular}

Seminars on hospital efficiency and
healthcare reimbursement
Enrollment in Stanford Faculty Development Rotations

Center workshop

Ultrasound diagnostics

Content on career development and burnout prevention

Assigned mentors

Perioperative medicine

Consultative medicine

Tulane University Leaders of residency-wide Ql teams $\quad$ Focus on value-added services
Content on leadership

Content on abstract and poster creation

Clinical coaching curriculum Assigned mentors

\begin{tabular}{|c|c|c|c|}
\hline $\begin{array}{l}\text { Virginia } \\
\text { Commonwealth } \\
\text { University }\end{array}$ & $\begin{array}{l}\text { QI methods } \\
\text { Stakeholder assessment } \\
\text { Leaders of longitudinal interprofessional } \\
\text { Ql projects }\end{array}$ & $\begin{array}{l}\text { Covered elsewhere in IM residency } \\
\text { program content }\end{array}$ & HM career panel \\
\hline $\begin{array}{l}\text { Wake Forest } \\
\text { University }\end{array}$ & $\begin{array}{l}\text { Ql methods } \\
\text { Ql rotation }\end{array}$ & $\begin{array}{l}\text { Business of Medicine elective } \\
\text { Didactic material on billing and coding }\end{array}$ & $\begin{array}{l}\text { Content on CV, interviewing, and contract } \\
\text { negotiation } \\
\text { 6-day leadership training workshop through } \\
\text { university }\end{array}$ \\
\hline
\end{tabular}

HM preceptorship

Rotations in postacute settings

HM preceptorship, including work with APPs Rotation in community hospital

Clinical journal club

Rotations

Geriatric medicine

Palliative medicine

Procedural elective

Perioperative medicine

Rehabilitation and nursing home units

NOTE: Abbreviations: APP, advanced practice provider; CV, curriculum vitae; HM, hospital medicine; IHI, Institute for Healthcare Improvement; IM, internal medicine; PGY, postgraduate year; QI, quality improvement; SHM, Society of Hospital Medicine. 
skills, such as curriculum vitae preparation and interviewing (Table 2). Many also provide content on venues for disseminating scholarly activity. The Colorado, Kentucky, New Mexico, and Tulane programs feature content on abstract and poster creation. Leadership development is addressed in several tracks through dedicated track activities or participation in discrete, outside-track events. Specifically, Colorado offers a leadership track for residents interested in hospital administration, Cleveland has a leadership journal club, Wake Forest enrolls HM residents in leadership training available through the university, and Minnesota sends residents to the Society of Hospital Medicine's Leadership Academy (Table 2).

\section{Clinical Rotations}

Almost all tracks include a clinical rotation, typically pairing residents directly with hospitalist attendings to encourage autonomy and mentorship. Several also offer elective rotations in various disciplines within HM (Table 2). The Kentucky and Virginia tracks incorporate working with advanced practice providers into their practicums. The Cleveland, Minnesota, Tulane, and Virginia tracks offer HM rotations in community hospitals or postacute settings.

HM rotations also pair clinical experiences with didactic education on relevant topics (eg, billing and coding). The Cleveland, Minnesota, and Virginia tracks developed clinical rotations reflecting the common 7-on and 7-off schedule with nonclinical obligations, such as seminars linking specific content to clinical experiences, during nonclinical time.

\section{DISCUSSION}

Our investigation into the current state of $\mathrm{HM}$ training found that HM track curricula focus largely on QI, health care economics, and professional development. This focus likely developed in response to hospitalists' increasing engagement in related endeavors. HM tracks have dynamic and variable structures, reflecting an evolving field and the need to fit into existing IM residency program structures. Similarly, the content covered in HM tracks is tightly linked to perceived opportunities within IM residency curricula. The heterogeneity of content suggests the breadth and ambiguity of necessary competencies for aspiring hospitalists. One of the 11 tracks has not had any residents enroll within the past few years-a testament to the continued effort necessary to sustain such tracks, including curricular updates and recruiting. Conversely, many programs now share track content with the larger IM residency program, suggesting HM tracks may be near the forefront of medical education in some areas.

Our study had several limitations. As we are unaware of any databases of HM tracks, we discussed tracks with professional contacts, performed Internet searches, and reviewed IM residency program websites. Our search, however, was not exhaustive; despite our best efforts, we may have missed or mischaracterized some track offerings. Nevertheless, we think that our analysis represents the first thorough compilation of HM tracks and that it will be useful to institutions seeking to create or enhance HM-specific training.

As the field continues to evolve, we are optimistic about the future of HM training. We suspect that HM residency training tracks will continue to expand. More work is needed so these tracks can adjust to the changing HM and IM residency program landscapes and supply well-trained physicians for the HM workforce.

\section{Acknowledgments}

The authors thank track directors Alpesh Amin, David Gugliotti, Rick Hilger, Karnjit Johl, Nasir Majeed, Georgia McIntosh, Charles Pizanis, and Jeff Wiese for making this study possible.

Disclosure: Nothing to report.

\section{References}

1. Glasheen JJ, Siegal EM, Epstein K, Kutner J, Prochazka AV. Fulfilling the promise of hospital medicine: tailoring internal medicine training to address hospitalists' needs [published correction appears in J Gen Intern Med. 2008;23(11):1931]. J Gen Intern Med. 2008;23(7):1110-1115.

2. Arora V, Guardiano S, Donaldson D, Storch I, Hemstreet P. Closing the gap between internal medicine training and practice: recommendations from recent graduates. Am J Med. 2005;118(6):680-685.

3. Glasheen JJ, Goldenberg J, Nelson JR. Achieving hospital medicine's promise through internal medicine residency redesign. Mt Sinai J Med. 2008;75(5): 436-441.

4. Wiese J. Residency training: beginning with the end in mind. J Gen Intern Med. 2008;23(7):1122-1123.

5. Glasheen JJ, Epstein KR, Siegal E, Kutner JS, Prochazka AV. The spectrum of community-based hospitalist practice: a call to tailor internal medicine residency training. Arch Intern Med. 2007;167(7):727-728.

6. Patel N, Brennan PJ, Metlay J, Bellini L, Shannon RP, Myers JS. Building the pipeline: the creation of a residency training pathway for future physician leaders in health care quality. Acad Med. 2015;90(2):185-190.

7. Kumar A, Smeraglio A, Witteles R, et al. A resident-created hospitalist curriculum for internal medicine housestaff. J Hosp Med. 2016;11(9):646-649.

8. Institute for Healthcare Improvement website. http://www.ihi.org. Accessed December 15, 2015. 